\title{
INTERACTIVE VIRTUAL OBJECTS (IVOs) FOR NEXT GENERATION OF VIRTUAL MUSEUMS: FROM STATIC TEXTURED PHOTOGRAMMETRIC AND HBIM MODELS TO XR OBJECTS FOR VR-AR ENABLED GAMING EXPERIENCES
}

\author{
F. Banfi ${ }^{1 *}$, A. Mandelli ${ }^{1}$ \\ ${ }^{1}$ Architecture, Built environment and Construction engineering (A.B.C.) Department, Politecnico di Milano, Milano, Italy - \\ (fabrizio.banfi; alessandro.mandelli)@polimi.it
} KEYWORDS: Interactive Virtual Objects (IVOs), Virtual Museum, eXtended Reality (XR), heritage documentation, 3D modelling,
Virtual Reality (VR), photogrammetry, Unmanned Aerial System (UAS),

\begin{abstract}
:
Virtual museums should not live on the internet through traditional applications sharing collections through simple panoramas or static images and descriptions but reach novel innovative and interactive forms of Virtual Reality (VR) and Augmented Reality (AR), providing a more creative, intimate, personal learning experience. For this reason, the authors propose a method based on advanced Information Technologies (IT) to fully return the tangible and intangible values of different type of works of art. The primary purpose of this study is to create a system of virtual environments through which the digital user, mainly the visitor of an unconventional museum, will be able to physically interact, through visual and tactile methods, with 3D digital models of sculptures, information, and art objects. Thanks to the integration of the latest 3D modelling and digital survey techniques with the Visual Programming Language (VPL) and eXteded Reality (XR) development platforms, authors propose new levels of interactivity between users and Interactive Virtual Objects (IVOs) capable of coming to life, sharing new forms of real-time human-computer interaction for VR-AR enabled gaming experiences and virtual museums, using multiple devices such VR headset, web-based AR platforms, mobile phones, tablets, and PC workstation.
\end{abstract}

\section{INTRODUCTION}

\subsection{General context}

The International Council of Museums (ICOM), an international organisation of museums and museum professionals, was created to raise awareness and protect the world's Cultural Heritage. Founded in 1948 on the initiative of Chauncey J. Hamlin, President of the American Association of Museums, this organisation considers the museum a permanent, non-profit institution serving society and its development. It is open to the public and carries out research concerning the material and immaterial testimonies of humanity and its environment; it acquires them, preserves them, communicates them and above all, exhibits them for study, education, and pleasure.

The museum is considered as the element of grouping, continuity (Sylaiou et al., 2010). It plays its role by preserving for the community and communicating with it through the objects (an ordered collection of works of art or scientific instruments, ancient finds, precious objects, testimonies of the history of one's country or customs, natural curiosities, etc.), which must be collected and treated with the utmost respect and scientific rigour. With the transformation of information and cultural systems, the advent of the latest generation technologies, 3D survey, eXtended Reality (XR), the selection criteria for the objects considered relevant, the purposes and forms for their organisation, exposure and dissemination have changed. Just think of the Building Information Modelling (BIM) process and the reengineering and digitisation process that has reformed the construction sector in recent years. Notably, the scan-to-BIM process applied to heritage buildings has been applied to archaeological sites, infrastructures, and monuments, not just heritage buildings. The added value of integrating innovative $3 \mathrm{D}$ survey methods such as terrestrial and aerial photogrammetry, laser scanning with advanced modelling techniques has allowed passing from simple
2D vector representations to digital models capable of faithfully representing reality and each type of survey artefact. In addition, thanks to the scan-to-BIM process applied to artefacts of high historical and cultural value (HBIM), it has also been possible to expand the information value of each architectural and structural element, reaching different types of experts such as architects engineers, archaeologists, and restorers (Bosché et al., 2015). For this reason, this article outlines a method capable of increasing the paradigm of the "utility" of digital models and digitised objects even for non-expert users such as virtual tourists and students through the latest generation XR techniques, digitising archaeological and ancient finds and trying to find new forms of interactivity and sharing of the tangible and intangible values of our built heritage.

1.2 State-of-the-art: from photogrammetric models to Digital Cultural Heritage (DHC)

Museums contribute to preserving the objects and memories that converge in the community's Cultural Heritage $(\mathrm{CH})$, through which society needs to be founded on history, on its past, to have its own characteristic identity. A museum, therefore, deals with scientific research, communication, and conservation. Consequently, the museum aims to: collect, safeguard, document, research, publish, introduce, explain, and finally disseminate knowledge to different levels of users.

In this specific field of application, digital photogrammetry has made it possible to lay the appropriate foundations for collecting metric and geometric information of any artefact in recent decades. In particular, innovative studies have made it possible to define processes capable of improving the level of detail and accuracy of digitised objects more and more (Volk et al., 2014). As is well known, photogrammetry is a technique that is mainly used in cartography, topography, and architecture. It allows you to metrically determine the shape and position of objects,

${ }^{*}$ Corresponding author 
identifying the spatial position of all the points of interest of the object considered. Although initially created to be used in the architectural survey, this technique is currently used for the topographical survey of the territory, mainly developing in the form of aerial photogrammetry.

The latest generation software able to manage many data and computer graphics have also allowed a simpler and faster use and lower costs. The advent of methods, software and technologies has made old optical equipment obsolete, favouring its commitment even in areas where it was rarely used in the past. In this context, the first result of the photogrammetric survey is a point cloud, which can be integrated with other 3D point clouds generated by different survey technologies such as laser scanners, total stations, and GPS.

This integration of tools and data allows professionals to interact with a single $3 \mathrm{D}$ environment characterised by different inputs and formats while maintaining the same georeferencing and project measurement unit. This technique, also known as Structure from Motion (SfM), is based on a calculation that allows the user to reconstruct the shape of objects through the automatic collimation of points from a set of photos. The SfM extracts the notable points from the individual images, deduces the photographic parameters, crosses the recognisable points on several images, and finds the coordinates in the space of the points themselves based on computer vision algorithms.

The extraction of the "key points" is helpful in the processing of the point cloud and the next phase, the creation of a textured mesh model. In the field of Digital Cultural Heritage (DCH) over the years, this specific methodology allowed to lay the appropriate foundations for correct digitisation of architectural and structural elements, pushing more and more professionals to define methods capable of replicating even the smallest artefacts.

Some studies have made it possible to distinguish and optimise digitisation and modelling techniques, identifying the pros and cons of mesh models. In particular, from a digital model point of view, digital photogrammetry only allows the creation of a textured mesh model.

On the other hand, it was found that a mesh is not manageable and automatically recognised as a BIM object by major applications such as Autodesk Revit and Graphisoft ArchiCAD. The leading cause is to be attributed to its composition. A mesh model is composed of a dense network of polygons and elementary surfaces of triangular geometry. Its size is too heavy for BIM platforms and cannot be transformed into an object capable of receiving information.

Consequently, recent studies have made it possible to define HBIM digitisation techniques, scan-to-BIM and Grades Of Generation (GOG) (Banfi, 2017) capable of transforming simple points from the 3D survey into BIM parameter objects. The primary data sources used in these studies are geometric entities such as points, surfaces, and solids that can be automatically transformed into informative models capable of communicating each material, physical, mechanical, historical, and cultural characteristics of the elements. Furthermore, recent studies have defined methods that could benefit from digital photogrammetry and obtain digital models that can also communicate different types of information using different devices (laptops, PC workstations, mobile phones) and software application (Chen et al., 2020). However, the step not yet thoroughly investigated is the one related to how to transform a textured mesh into an intelligent object for the latest generation XR and BIM projects, interacting and responding to user input.

For this reason, this study outlines a process trying to improve the interoperability between the outputs produced by the digitisation process and enhancing the usefulness of photogrammetric models for other forms of model sharing, such as virtual museums and $\mathrm{XR}$.

\subsection{State-of-the-art: from virtual museum to XR}

We all know how a museum is made, it is a structure which can be divided into rooms and each room contains works of different types. Usually, the works can be accompanied by a description, caption, audio headphones with a built-in guide or a guide that he can tell us about the work we see at that precise moment.

On the other hand, the work is decontextualised, adapted, and forced into a new environment, consequently losing its real context's historical and cultural charm. In addition, visit times must respect the needs and trends of the flow, safety distances imposed by the global health emergency, avoiding staying too long in front of a work and promoting sustainable use of the rooms (Atsiz, 2021). For these cons, recently, the creation of virtual museums alongside an actual museum has turned out to be a solution capable of reaching many users even at a distance, exponentially increasing the knowledge and dissemination of historical and cultural information, renewing the interest in the works of art placed inside (Kwok, Koh, 2020).

The virtual museum had its origins in the academic field by the student Nicolas Pioch, who in 1995 conceived and created the WebMuseum (Ibiblio, 2021), a network for the dissemination of works of art. After this project, sites related to art galleries began to spread with images and written captions. By now, almost all museums in the world (artistic, archaeological, anthropological, or scientific-technical) have created their own website, often conceived as a digital representation of the real museum, with very similar structure and contents (Huhtamo, 2013). There is no shortage of sites released from real museum institutions and multimedia databases, organised in consortia and non-profit organisations, which offer the digitised cultural heritage of several museums.

In this context, thanks to the integration of advanced digitisation techniques such as the scan-to-BIM process, VR and AR have made it possible to reconstruct the objects and their historical context. Interesting studies have shown the potential of these techniques, recreating objects, buildings, small, medium, and large artefacts such as entire ancient cities and complex urban scenarios. Over the years, different types of virtual museums have been seen, from the completion or replica of the real museum to the one exclusively on-line, where applications based on 360 panoramas simulate a virtual path. On the other hand, the recent form of the virtual museum does not allow high levels of interactivity between the user and the museum itself. In fact, a virtual museum can be the collection and sharing of a large number of objects: from paintings, photographs to large and small sculptures accompanied by an information apparatus. Forms of VR-AR are not yet fully integrated into the museum reality as they require high skills in multiple disciplinary and application sectors such as computer graphics, computer programming, digital representation using advanced modelling, restoration, and archaeology.

\subsection{Research objectives: the need to improve the information sharing for virtual museums based on high resolution 3D textured models and IVOs}

Choosing to create a virtual museum undoubtedly has different advantages, but it requires you to have in-depth knowledge in many disciplines and master different digital tools, which go beyond the simple creation of a website based on panoramas. The benefits can be the most varied: giving the possibility to every user in the world, to visit the museum and to personalise the visit, the itinerary, not being tied to entrance times, not having specialised personnel to supervise the rooms or that deals with security, collect works scattered all over the world, reconstruct 
objects or works or sites that have been lost through animations and 3D models.

As already briefly mentioned in the previous paragraph, through $\mathrm{XR}$, it is now possible to increase the level of intercompetitiveness of digital worlds between user and machine, enhancing the levels of communication through digital forms capable of sharing different types of data and formats.

Consequently, the understanding and IT management of digital models and the leading XR development platforms open new doors for architects, engineers, restorers, archaeologists, historians, students, virtual tourists, and museum curators, who for the most part do not have computer skills oriented to the development of specific IT applications (Hammady et al., 2021). For those reasons, this research intends to consolidate a method capable of orienting itself to any artefact and showing how different $3 \mathrm{D}$ objects coming from photogrammetry and 3D modelling can come to life in different XR ways. In this specific field of application:

- 3D modelling;

- $\quad$ Visual Programming Language (VPL);

- $\quad$ model interoperability;

were found to be the key elements to be able to make this transition. In fact, to be as credible as possible, a virtual museum or XR environment must possess specific characteristics such as (i) models with a high level of detail capable of corresponding to the objects exhibited in real museums, (ii) high-resolution textures able to show chromatic and authentic material values and (iii) the correct sizing in the virtual environment in relation to the user. These and many other requirements are defined by proper $3 \mathrm{D}$ modelling. The latter one articulated in its most advanced forms, must be associated with the VPL, which allows it to switch from a static mesh to an IVO. Finally, the appropriate use of exchange formats (from modelling software to XR development platforms) is crucial for correct visualisation, navigation and interaction with the digital environment created

Accordingly, this study proposes a digitisation process as sustainable as possible concerning a current technological reality, integrating several forms of photogrammetric digitisation (terrestrial and aerial) with advanced modelling techniques and development of VR-AR environments where the end-user can interact with new forms of IVOs.

In the following paragraphs, the methods applied to two research case studies describe how simple textured mesh models can be transformed into smart XR objects capable of communicating different types of information, coming to life, and interacting with user input.

Furthermore, in order to show how the process is applicable to different 3D realities and objects, this article summarises and describes the method applied for two case studies of different nature, both in geometric, historical and cultural terms: the Arco della Pace in Milan and the archaeological site of Bajardo, Italy. Both case studies required a cognitive investigation of their historical heritage and an in-depth analysis of different historical sources and manuscripts.

In particular, for the Arco della Pace, in-depth study of historical treatises allows authors to understand the history of the city of Milan described and reported appropriately in the decorative apparatus of the monument (Giani, 1988; Gaberden 1850; Reina, 1839), while for the archaeological site in Bajardo, interviews and investigations for archives, and websites have allowed the identification and collection of information that were in danger of being lost from generation to generation.

\section{THE RESEARCHCASE STUDIES: THE ARCO DELLA PACE OF MILAN AND THE ARCHAEOLOGICAL SITE OF BAJARDO}

2.1 The growing demand for new forms of digitisation for built heritage and virtual museums: the Covid-19 year and the new global awareness

In the year of Covid-19, museums lose $75 \%$ of visitors and $78 \%$ of revenues. With about four months behind closed doors in 2020, the Italian state museums, monuments and archaeological areas present the bill, and it could only be negative: $-75.67 \%$ visitors and $-78.98 \%$ net revenues for a total of $41,991,929.03$ euros for the 268 institutions monitored by the Sistan (National Statistical System of the Ministry of Culture). It would help if you went back to 1996 to find similar collections. At the time, there were 166 institutions surveyed, and in any case, 25 years ago, the number of visitors was double. Fortunately, this figure must be enriched with all the digital activity -from virtual tours to do-it-yourself exhibitions, from talks with curators and directors to social activity- which animated the long months of lockdown. Technologies have helped keeping the contact between cultural institutions and communities alive but opening to digital has meant "going out" of one's habits to enter an unknown space. Not everyone knows the grammars and not everyone already structurally has the professional skills prepared and dedicated. The pandemic, through digital, has shown new fragility of state museums, which must quickly be overcome. But returning to the physicality of the visits, for the Colosseum and Pompei, the data are the worst of all, they lose between $85 \%$ and $84 \%$ for visitors and revenues, yet the visits were outdoors.

Table 1 shows the data referred to single or cumulative tickets issued respectively for each Institute or Museum Circuit. Cumulative tickets are not included in those of the individual museum institutes making up the Circuit. The object of the investigation is the ticket sold and not the visitor's access, given the impossibility of detecting the entrance. From the ticket count n. 464,639 for a gross amount of $6,723,768.73$ euros and a net amount of 5,781,605.37 euros. These are tickets transformed into vouchers and not used during the year 2020, which will eventually be counted at the time of their use.

\begin{tabular}{|c|c|c|c|c|}
\hline Museum & City & $\begin{array}{l}\text { Total } \\
\text { Visotors } \\
2019 / 2020\end{array}$ & \multicolumn{2}{|c|}{$\begin{array}{l}\text { Delta } \\
\text { Introitus } \\
2019 / 2020 \\
\end{array}$} \\
\hline Gallerie degli Uffizi & Florence & 1.206 .175 & -73 & -76 \\
\hline $\begin{array}{l}\text { Parco archeologico del } \\
\text { Colosseo }\end{array}$ & Rome & 1.085 .907 & -86 & -85 \\
\hline $\begin{array}{l}\text { Parco archeologico di } \\
\text { Pompei }\end{array}$ & Pompei & 597.280 & -85 & -85 \\
\hline $\begin{array}{l}\text { Galleria dell'Accademia } \\
\text { di Firenze }\end{array}$ & Florence & 319.451 & -81 & -85 \\
\hline Reggia di Caserta & Caserta & 293.891 & -60 & -63 \\
\hline $\begin{array}{l}\text { Museo delle Antichità } \\
\text { Egizie (gestito dalla } \\
\text { Fondazione) }\end{array}$ & Torin & 241.139 & -72 & -76 \\
\hline $\begin{array}{l}\text { Museo Nazionale di } \\
\text { Castel Sant'Angelo }\end{array}$ & Rome & 219.844 & -82 & -81 \\
\hline $\begin{array}{l}\text { Villa Adriana e Villa } \\
\text { D'Este }\end{array}$ & Tivoli & 218.998 & -70 & -69 \\
\hline Galleria Borghese & Rome & 153.068 & -73 & -75 \\
\hline Musei Reali & Torin & 141.709 & -71 & -68 \\
\hline
\end{tabular}

Table 1. The top 10 Italian state museums, monuments, and paid state archaeological areas (Il Sole 24 Ore, 2021). 


\subsection{The monument Arco della Pace in Milan, Italy, and its decorative complexity}

In the centre of the vast Piazza Sempione, which serves as the head of Corso Sempione, stands the Arco della Pace, begun in 1807 by Luigi Cagnola, with on the sides the toll booths built both for the collection of the duty and for the delimitation of the urban territory compared to the campaign. The monument consists of three arched doors, flanked by colossal, fluted Corinthian columns and surmounted by the Sestiga della Pace, bronze by Abbondio Sangiorgio, a chariot pulled by six horses that welcomes Minerva in Pace, a statue over 4 meters high and heavier more than 10 tons, accompanied by four "Victories on horseback" by Giovanni Putti. In Baveno granite, with Crevola d'Ossola marble cladding, 25 meters high and 24 meters wide, the imposing work is inspired by Roman models dear to the neoclassical culture of the $18^{\text {th }}$ and early $19^{\text {th }}$ century and represents a high example of neoclassical art. Above the entablature, the four main rivers of the Lombardy-Veneto region (Po, Ticino, Adige and Tagliamento) are depicted. A rich plastic decoration, in the academic style of the early 1800 s, takes place on the fronts and sides with exuberant ornaments and bass reliefs, mostly on the themes of the restoration. With the return to the Habsburgs, its commemorative purpose also changed: from Arco della Vittoria, in memory of the battle of Jena in Thuringia (Germany) won by the French in October 1806, to Arco della Pace. On the two fronts of the attic, there are the inscriptions of the entry of Napoleon III and Vittorio Emanuele II of 1859, which replaced the previous inscriptions made for Francesco I and Ferdinando I. Synthetically, the case study of the Arco della Pace turned out to be a useful application field for the development of an XR project capable of telling, showing, cataloguing, and archiving the story told in its unique decorative apparatus. As described in the following paragraphs, the method made use of a UAS survey, which made possible to survey unique works of art as accurately and truthfully as possible (Figure 1).

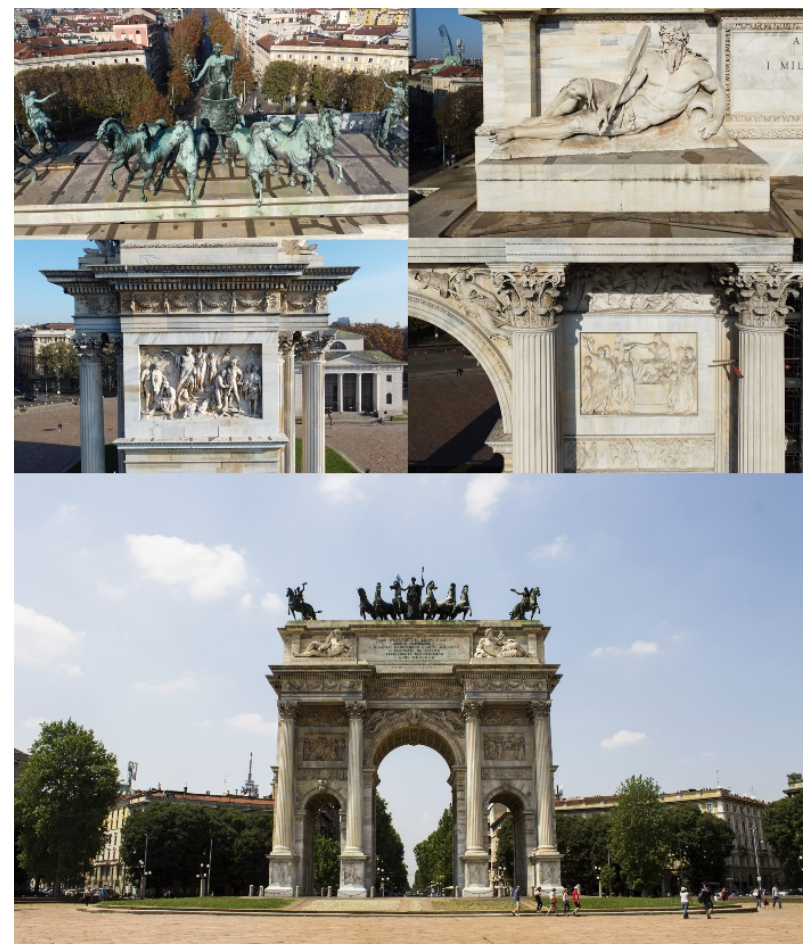

Figure 1. The Arco della Pace in Milan and its decorative apparatus. Photos coming from UAV survey.

\subsection{The archaeological sites of Bajardo and its historical- cultural background}

The first certain dating of the building dates to 1245 , but it is thought that it may have been built on a pre-Christian temple dedicated to Celtic cults. On February 23, 1887, and a large part of the faithful of the country (212) died due to an earthquake that struck a large part of Italy. Today the place presents itself with an austere and welcoming aspect at the same time, where the living stone characterises the architectural and structural elements handed down over the centuries. On one side, the altar on which a simple wooden crucifix still stands, on the other the chapel of St. Antonio, miraculously unharmed during the earthquake, the only testimony of the original Baroque character of the building before the collapse.

The complex, with its particular aspect, is in turn immersed in a magical context. To the west, a ruin of a portico with columns and strange capitals with an ambiguous oriental flavour, evidence of the passage of ancient stone masters of Cenova, who made these figures with peculiar features the distinctive feature of their highly appreciated art. And again, always to the west, a terrace that overlooks the Ligurian Sea directly, which the eye reaches accompanied by an expanse of mountains, gorges and hills that almost seem to imitate the waves.

From here, on clear days, you can see as far as the French coast. To the north, on the other hand, the Balcony on the mountains, a large grassy square that offers a breath-taking view of the Maritime Alps. All around the "caruggi" of the medieval village make their way which, between arches and secret passages, draw a topography to be discovered step by step. The Old Church is a place full of magnetism and vibrations, with a mysterious atmosphere, probably the legacy of an ancient history that seems to hover over the site. A historic place, with a mythical past and a vivid present, in fact, in the summer, it becomes a place for cultural shows and meetings, open-air cinema and suggestive Celtic rites (Alia, Cuomo, 2017) (Figure 2).

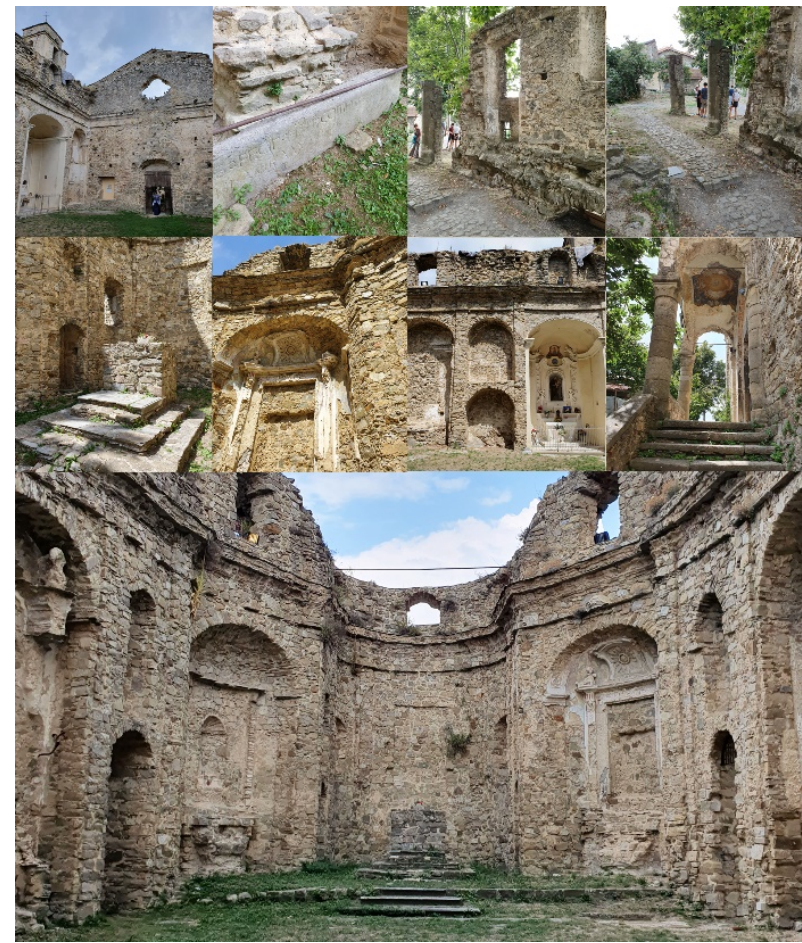

Figure 2. The archaeological site of Bajardo and its unique archaeological artifacts. 


\section{VIRTUAL OBJECTS AND HIGH-RESOLUTION 3D MAPPING FOR VR-AR ENABLED GAMING EXPERIENCES}

\subsection{D survey of the research case studies, from primary and} secondary data sources to high resolution textured models

The survey of the Arco della Pace in Milan considered the integration of different sensors and instruments. Namely, the 3D survey was performed using a consumer camera, a consumer Unmanned Aerial Vehicle (UAV) and a total station to check the accuracy of the final results. These instruments let the operator to collect the so-called "primary data sources," i.e. the information coming directly from the object, its dimensions, colour, position and peculiar characteristics. The "secondary data sources" refer to the collection of information coming from the bibliography and literature about the monument. The integration of primary and secondary data sources is always fundamental in approaching a real object's description, whether it is a small artefact or a whole building.

In the case of the Arco della Pace, the first step was to collect the images from the ground for the photogrammetric elaboration, supported by a topographic net around the monument. These data and three different monographs about the monument were enough to describe it through an affordable, accurate and textured 3D digital model. The upper parts that were not visible from the ground due to the overhangs of the friezes were reconstructed thanks to the precise drawings and measurements of the design project.

However, the authors decided to plan an aerial survey to complete the missing elements of the arch, i.e. the statues and the bass reliefs that represent a key characteristic of the monument. Planning a flight in the city centre of a city as Milan is not trivial: there are many variables that must be considered before approaching such a task.

The current regulation about UAV in Italy does not allow the flight of drones in crowded and sensitive places (ENAC, 2021; EASA, 2021). The city centre of Milan (D-flight, 2021) falls back in five different restriction areas: i) LI-R9 Milano-Città, ii) Milano/Bresso 18/36, iii) Milano/Linate 18/36, iv) Linate Aerodrome Traffic Zone (ATZ), and v) Linate Control Traffic Region (CTR). Each of these areas has its own rules for flight and the most restrictive one is LI-R9 Milano-Città where the flight is completely forbidden for security reasons. Actually, temporary permission can be obtained by the city's authorities by submitting all the necessary documents and a high detailed relation that describes the activity, the timetable of the flights, the risk assessment and the precautions taken to decrease the level of the risk.

Moreover, the person in charge for the flight must obtain a certificate for driving drones after passing an on-line test and a practical exam. The authors, both holding a piloting license, provided the material above-mentioned to the prefecture of Milan that has the faculty to issue or not the permission, then the permission must also be approved by ENAC. Even if the prefecture issues the permission, the Authority can revoke it. After a month from the submission of the request, the survey activities described in the relation received a positive judgment by the two authorities. The positive judgment was achieved because it was considered a sufficient buffer area around the monument, and the date chosen for the survey activity fell into the lockdown period linked with the Covid-19 pandemic. Therefore, all the shops restoration activities were closed and there were no crowds around the monument since the prohibition to stay in public spaces without a proven reason. Nevertheless, since the Italian regulation considers special rules for UAVs weighing less than 250 grams, it was decided to use a UAV with this peculiar characteristic, namely the DJI Mavic Mini.

The data processed were composed by 229 images acquired from the ground with a Canon EOS 1100D coupled with an $18 \mathrm{~mm}$ lens, 945 photos taken during four different flights around the arch, and some architectural points measured on the four façades from a simple topographic network around the monument, measured with the total station Leica TS12.

The distances of the acquisition were calculated with the formula $c: D: p x: G S D$, where $c$ is the focal length, $D$ is the distance from the object, $p x$ is the pixel size of the sensor, and GSD is the Ground Sample Distance, to achieve a 1:50 drawing scale. The GSD for 1:50 scale was assumed equal to $1 \mathrm{~cm}$, multiplying the plotting error $(0.2 \mathrm{~mm})$ by the scale's denominator.

As a result, the distances calculated for each sensor to reach a GSD equal to $1 \mathrm{~cm}$ are respectively $27 \mathrm{~m}$ for the DJI Mavic Mini and $35 \mathrm{~m}$ for the terrestrial survey.

The results are theoretical values considering ideal conditions with a camera placed on a tripod without external interferences. In the practical activity, it is suggested, even in good conditions, to halve the results obtained to assure the reaching of the GSD designed.

Regarding the UAV survey, once the distance was calculated, the path of the flight followed as much as possible parallel vertical strips. The vertical (longitudinal) overlap of the images was controlled, setting the auto interval acquisition of the images equal to 2 seconds, the side (transversal) overlap was valued directly on the screen by the video operator of the drone.

\begin{tabular}{|l|c|c|}
\cline { 2 - 3 } \multicolumn{1}{c|}{} & DJI Mavic Mini & Canon D1100 \\
\hline Sensor size $($ pixel) & $4000 * 3000$ & $4272 * 2848$ \\
\hline Sensor size $(\mathrm{mm})$ & $6.48 * 4.86$ & $22,2 * 14,7$ \\
\hline Pixel size $(\mathrm{mm})$ & 0.00162 & 0.00520 \\
\hline Focal length $(\mathrm{mm})$ & 4.49 & 18 \\
\hline Flight time $(\mathrm{min})$ & 28 & $\mathrm{x}$ \\
\hline Proximity sensors & Downwards & $\mathrm{x}$ \\
\hline
\end{tabular}

Table 2. Specs of the sensors used for the photogrammetric survey.

The photogrammetric data were elaborated using Agisoft Metashape Pro (version 1.7.2 build 10270), the architectonical points measured with the total station were used to optimise the project and to check the accuracy of the result. The terrestrial and UAV survey were divided in two different chunks and merged before the generation of the mesh model.

Once the photogrammetric elaboration was completed, the primary source data, namely the dense point cloud and the high resolution meshes of the statues, were processed to obtain a NURBS model using different software and exchange file formats (Piegl, Tiller, 1996). The dense point cloud was imported as .e57 file into Mc Neel Rhinoceros 7, here it was possible to make some slices through the point cloud and reconstruct the primitive geometries. This phase was also supported by the bibliography and technical drawings of the arch. A different pipeline was followed for the generation of the NURBS statues. The models were exported in .obj file format and imported into Geomagic Design X. The auto-surfacing command lets to adapt NURBS geometries on the mesh objects, capturing at best the original shape. Once the NURBS were fixed from a topological point of view, they were exported in .igs format and imported in Rhinoceros 7. This workflow preserves the dimensions and the georeferencing of the models, so it was not necessary to move or scale the objects in the 3D modelling environment. The models were finally textured using the images and the orthophotos coming from the photogrammetric survey (Figure 3). 


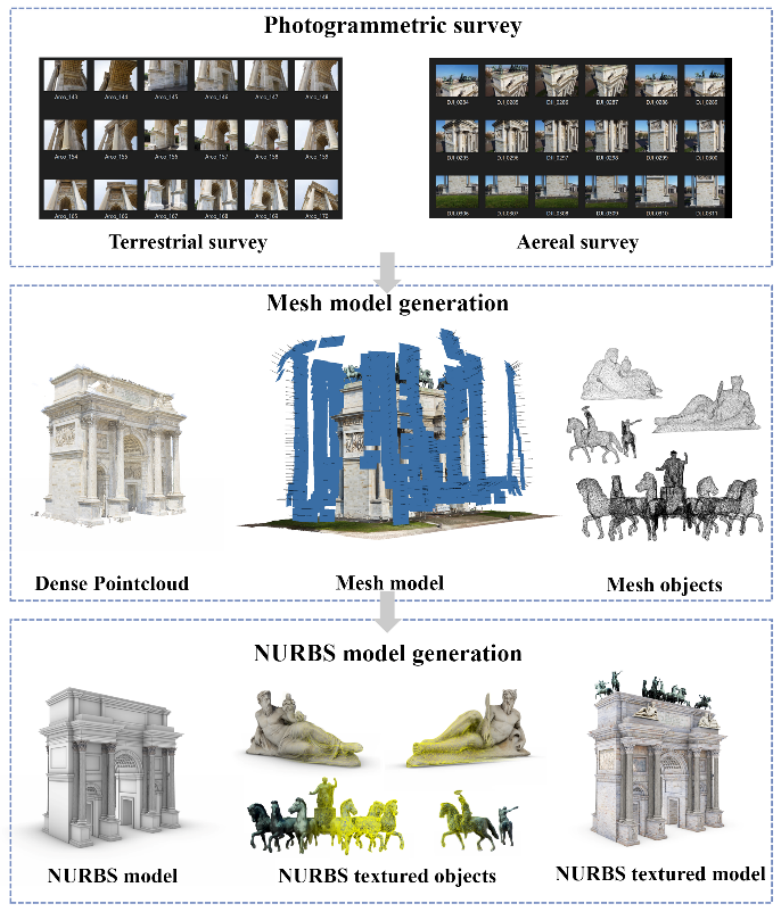

Figure 3. The survey and post-processing steps of the Arco della Pace: from terrestrial and aerial photogrammetry to NURBS textured models.

For the case study of the archaeological site of Bajardo, terrestrial photogrammetry and the creation of many textured mesh models made it possible to lay the foundations for creating an orientable 3D environment for the development of the VR-AR projects. Digital 3D survey techniques quickly highlighted the shape, dimensions from a morphological and typological point of view of the altar, apses, external and internal walls, antiquities, and the entrance characterised by a sail vault. 3D survey obtained an accurate non-invasive digital data collection, achieving the best point clouds for each architectural and structural element. The importance of constructive techniques has played a key role in the reverse engineering of each architectural component. The features of the building have been identified directly on the field thanks to historical documents and 2D drawings, which completed the interpretive analysis of the building and materials used for the construction. In this context, as is known, at the beginning of the transformation process, point cloud processing applications lead to an automatic generation of mesh models. Software as Agisoft Metahsape and ContextCapture enabled the automatic creation of mesh from dense point cloud thanks to specific algorithms that recognise the $3 \mathrm{D}$ points like the data source to generate the mesh models. Mesh interpreted the complexity of the shapes through the union of points through polygons based on different algorithms. It found that mesh polygons represented a huge constraint for the model generation and the subsequent management of mesh models in HBIM/VR/AR objects. For this reason, thanks to the application of GOG 9 and 10 it has been possible to transform simple meshes into geometrical models capable of accommodating highresolution orthophotos. Furthermore, this approach also made it possible to better orient digital models for the next phase of VRAR development: thanks to specific exchange formats it has been possible to outline a sustainable transformation process without remodelling or remapping objects (Figure 4). Starting from the photogrammetric outputs, the models were transformed into the following formats: Wavepoint OBJ, FBX, 3DM, RVT, updated FBX for VR and AR.

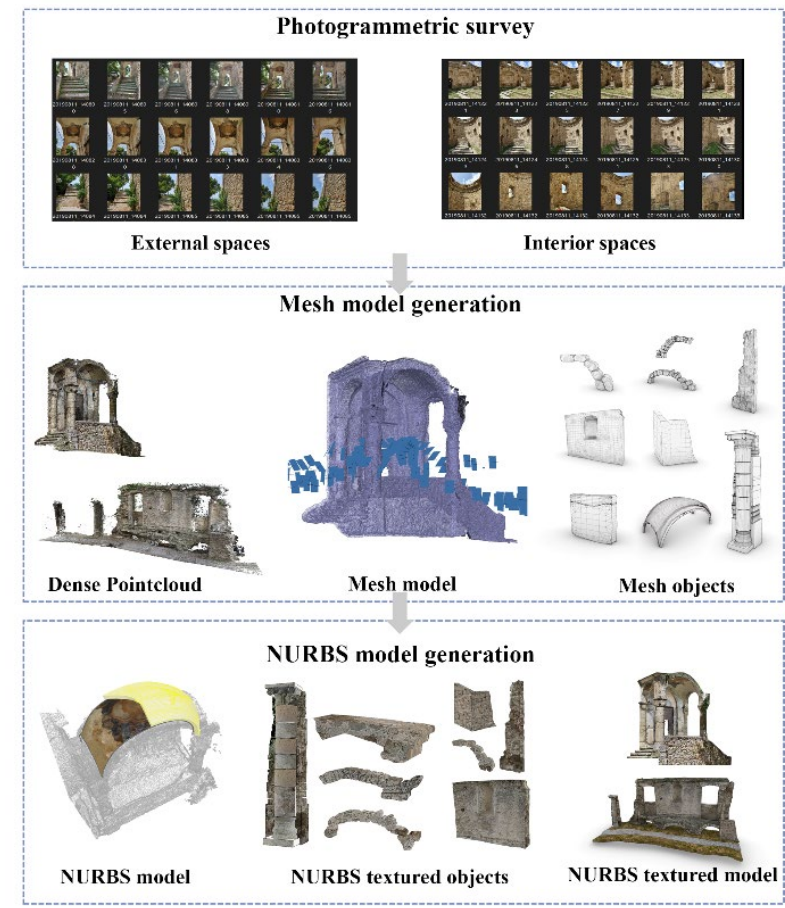

Figure 4. The 3D survey and post-processing steps of the St. Nicolò Archeological Site, Bajardo: from terrestrial photogrammetry to NURBS textured models.

\subsection{From high resolution textured models to VPL}

The process of transforming textured mesh model into an object capable of interacting with user input was determined through the development of specific visual scripting, also known as Blueprints. Blueprints is Unreal Engine visual scripting system accessible to different levels of developers, from professionals to advanced users to beginners.

As mentioned in the previous paragraphs, programming in $\mathrm{C}++$ can be a daunting task for beginners and Architecture, Engineering and Construction (AEC) professionals (Alizadehsalehi, Hadavi, Huang, 2020). Therefore, for developing the code in $\mathrm{C}++$, the authors implemented several Blueprints using nodes, events, actions, and conditions linked together in visual form. This IT development allowed the authors to transform simple textured mesh models into IVOs composed of nodes that have input and output values. Furthermore, the Blueprint-based visual workflow allows the development of different codes linked together, giving life to the static 3D objects from photogrammetry, controlling them through a digital compiler.

For the research case studies, specific Blueprints have been developed, integrating different functions, actions, and movements for different 3D objects.

Creating a virtual museum based on new forms of humancomputer interaction had to consider the accessibility and use of additional information associated with various objects (Helander, 2014). For instance, the possibility of leafing through books able to describe the decorative apparatus of the monument has led the authors to develop functions associated with a specific 3D object to make the book itself browsable, which in turn has been mapped with the recovered historical texts, drawings, animation, and audios. Another crucial Blueprint for managing several museum rooms has been developed to teleport the user (in first or third person) between one level and another without carrying out long distances in the virtual environment (Figure 5). 
Consequently, other Blueprints have been developed to improve the interactivity level of the virtual museum and the related IVOs placed in each level room. The following figure shows one of the main Blueprints created in relation to the designed XR environment.

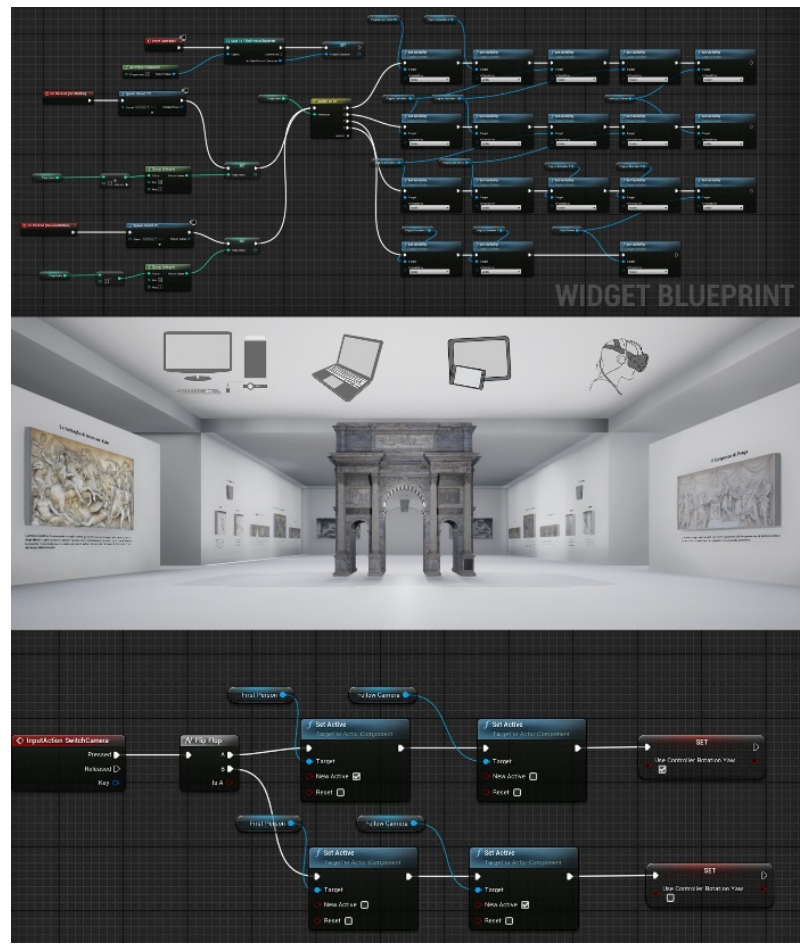

Figure 5. The virtual museum of the Arco della Pace and the main Blueprints developed for different type of IVOs and devices.

\subsection{IVOs and human-computer interaction based on scan- to-BIM-to-XR objects}

The development stage of the virtual museum had to consider other technological aspects. With the development of the Blueprints, different tests were conducted regarding the level of immersion of the two projects. It was found that the levels of interactivity highly depended on the device used. In this context, the test and the use of VR headsets, workstations, mobile phones, and laptops were decisive for obtaining a complete virtual experience both from a technical and an informative point of view. In fact, one of the objectives of the two virtual museums was to tell the historical and cultural background found during the study and deepening of the case studies. An open approach was chosen for the Arco della Pace, capable of developing new levels, rooms, Blueprints, and information associated with them over time. This development required Unreal Engine platform capable of allowing continuous development over time, without physical limits related to the size of the model. Integrating the VR headset with a gaming-oriented workstation was crucial in developing a large XR project. More portable forms were also investigated for the case study of the archaeological site. Figure 6 shows the tools used to navigate both virtual museums, passing from different VR-AR interaction and devices forms according to the IVOs created. For mobile devices, two solutions have been developed to test the development limits of the geometric environments in terms of the number of polygons and textured model's size. AR libraries have been oriented for iOS and Android devices using OBJ and FBX formats (first solution). Clicking the AR button, the experience shows an auto generated
QR code that viewers can scan to automatically open the model in AR. The second solution considered mobile game development. To create and deploy an Android project, authors needed to install several Android development prerequisites and ensure that the device was ready for testing.

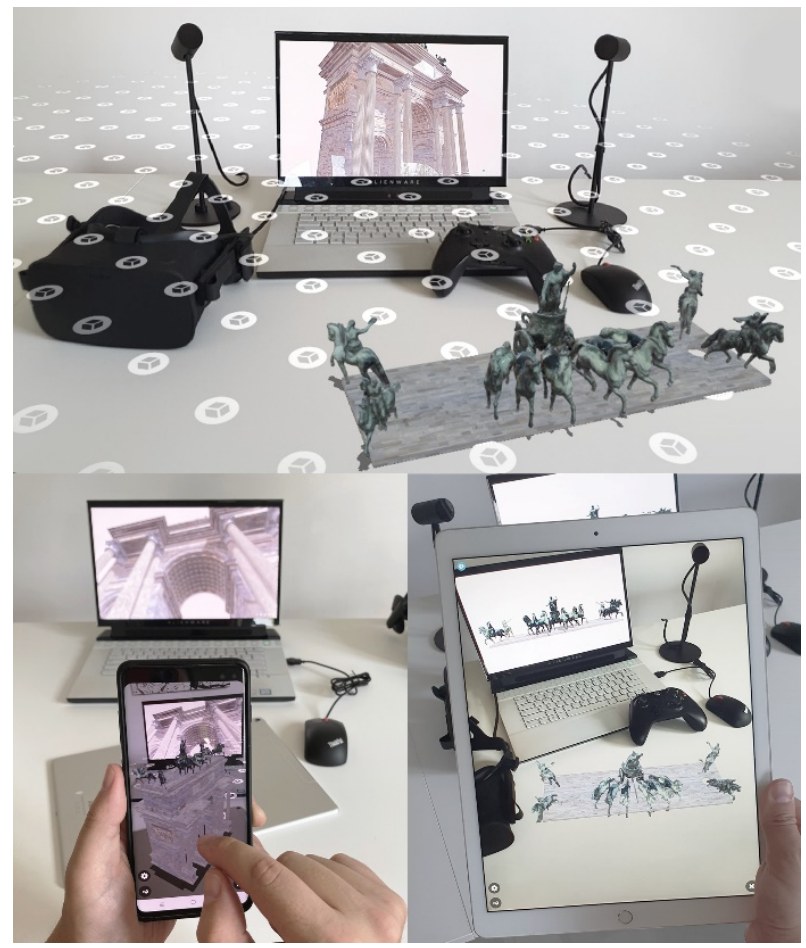

Figure 6. Human-computer interaction and virtual museums of both research case studies, from IVOs to VR headsets, mobile phones, and web-based AR libraries.

Following the guide in Setting Up Android SDK and NDK for Unreal to install Android Studio and set up the required SDK components for Android development in Unreal, has been possible to go beyond a simple web platform and reach a proper serious game. In this way, developing a training tool where the serious and playful aspects are in balance has been possible.

The desire to create an effective and pleasant training experience was the main goal of this phase. On the other hand, it was difficult to distinguish between entertainment games because it is often the player himself that determines the formative aspect. Interactive virtual simulation is also often considered a serious game. Both have been found to have the fundamental purpose of developing skills and competencies to be applied in the real world through exercise in a simulated environment.

\section{RESULTS AND CONCLUSION}

The proposed process is structured by levels of interoperability that allow the user to switch from a static textured model coming from aerial or terrestrial photogrammetry into IVOs capable of increasing the human-computer interaction between virtual museums, XR users and different types of devices, from VR headset to mobile phone. To demonstrate the reliability, sustainability and applicability of the method, different types of photogrammetric textured mesh models were transformed into objects capable of being associated with different types of visual scripting. In particular, both the project of the Arco della Pace monument and the Bajardo archaeological site project have made it possible to identify exchange formats capable of transmitting high Levels Of Detail (LOD) and Level Of Information (LOI) for 
different types of devices, from workstations to mobile phones (VR-AR). In this context, great flexibility of NURBS textured models has been found, unlike mesh models that still require long cleaning, decimation, and simplification processes, especially those oriented towards web platforms. For these reasons, the workflow proposes digital transformations of the models with the aim of increasing the level of modelling automation as much as possible, passing from simple mesh formats to exchange formats capable of interoperating with XR development platforms such as Unreal Engine, Unity and Twinmotion. In addition, the great advantage of VR over AR was found.

VR allows the implementation of rich interactive projects in terms of content, size of the objects and textures used. On the other hand, AR still requires web platforms and apps through which it is not possible to overcome certain limits of polygons and size of the models $(50,100,200 \mathrm{Mb})$, thus limiting the use of scan-to-BIM models aimed at managing high LODs. Furthermore, LOI is still very low, where at most, the end-user can interact with very concise descriptive panels and development functions.

Future developments will improve the scan-to-BIM-to-XR process, and the level of interoperability oriented to different types of analysis such as VR and AR. In this context, the latest generation devices such as the VR headset and mobile phones will require specific $\mathrm{XR}$ and visual scripting projects to make human-computer interaction as fluid as possible. Consequently, XR development platforms, Blueprint and IVOs will play a fundamental role in the transmissibility of content and improving the world of virtual museums and DCH in general.

\section{ACKNOWLEDGEMENTS}

The authors thank the Municipality of Milan and Bajardo (Italy), ENAC and Dr. Michela Sartori Prefettura of Milan Area I Ordine e Sicurezza Pubblica for the authorizations to fly. The authors thank Arch. Jacopo Alberto Bonini and the students Mohamed Jaabar and Luca Melotto for the content implementation process of the virtual museum of Arco della Pace, Milan, Italy.

\section{REFERENCES}

Alia, A., \& Cuomo, L., 2017. Bajardo 360: strategie di rigenerazione per un borgo dell'entroterra ligure.

Alizadehsalehi, S., Hadavi, A., \& Huang, J. C., 2020. From BIM to extended reality in AEC industry. Automation in Construction, 116, 103254.

Atsiz, O., 2021. Virtual reality technology and physical distancing: A review on limiting human interaction in tourism. Journal of multidisciplinary academic tourism, 6(1), 27-35.

Banfi, F., 2017. BIM orientation: Grades of generation and information for different type of analysis and management process, in: International Archives of the Photogrammetry, Remote Sensing and Spatial Information Sciences - ISPRS Archives. International Society for Photogrammetry and Remote Sensing, pp. 57-64. https://doi.org/10.5194/isprs-archives-XLII2-W5-57-2017.

Bosché, F., Ahmed, M., Turkan, Y., Haas, C. T., \& Haas, R. (2015). The value of integrating Scan-to-BIM and Scan-vs-BIM techniques for construction monitoring using laser scanning and
BIM: The case of cylindrical MEP components. Automation in Construction, 49, 201-213.

Chen, M., Feng, A., McAlinden, R., \& Soibelman, L. (2020). Photogrammetric point cloud segmentation and object information extraction for creating virtual environments and simulations. Journal of Management in Engineering, 36(2), 04019046.

D-flight, 2021, https://www.d-flight.it/new_portal/ (7 June 2021)

ENAC, 2021, https://www.enac.gov.it/sites/default/files/allegati (2 June 2021)

EASA, 2021, https://www.easa.europa.eu/document-library/ (2 June 2021)

Gaberden, F. J., 1850. Der Friedensbogen in Mailand: Arco della pace, Joh Meiners.

Giani, G., 1988. L'Arco della pace di Milano. Di Baio Editore.

Hammady, R., Ma, M., Ziad, A. K., \& Strathearn, C. , 2021. A framework for constructing and evaluating the role of MR as a holographic virtual guide in museums. Virtual Reality, 1-24.

Helander, M. G. (Ed.), 2014. Handbook of human-computer interaction. Elsevier.

Huhtamo, E., 2013. On the origins of the virtual museum (pp. 134-148). Routledge.

Ibiblio, 2021, http://www.ibiblio.org/wm/ (14 June 2021)

Il Sole 24 Ore, 2021, https://www.ilsole24ore.com/art/nell-annocovid-musei-perdono-75percento-visitatori-e-78percentointroiti-AEkEcNG?refresh_ce=1 (14 June 2021)

Kwok, A. O., \& Koh, S. G., 2020. COVID-19 and extended reality (XR). Current Issues in Tourism, 1-6.

Piegl, L., \& Tiller, W., 1996. The NURBS book. Springer Science \& Business Media.

Reina, G., 1839. Descrizione dell'Arco della pace in Milano. Tipografia Ronchetti.

Sylaiou, S., Mania, K., Karoulis, A., \& White, M., 2010. Exploring the relationship between presence and enjoyment in a virtual museum. International journal of human-computer studies, 68(5), 243-253.

Volk, R., Stengel, J., \& Schultmann, F. (2014). Building Information Modeling (BIM) for existing buildings - Literature review and future needs. Automation in construction, 38, 109127. 